Sección Sur-Sur

\title{
An Approach to the Effects of Modern Art on the Evolution of Iranian Contemporary Typography
}

\author{
Un acercamiento a los efectos del arte moderno en la evolución de la tipografía contemporánea iraní
}

Maryam Rafiei | Eram Institute of Higher Education - IRAN |

Master of Graphic, Eram Institute of Higher Education, Faculty of Graphic, Shiraz, Iran. E-mail: baranm656540@gmail.com

Jamshid Arasteh | Eram Institute of Higher Education - IRAN |

PHD. Student of Communication and media study, Faculty member of Eram Institute of Higher Education, Faculty of Graphic, Shiraz, Iran E-mail: jamshidarasteh@ gmail.com

\begin{abstract}
Today, letter design is no longer just a way to convey information, its visual and structural features is not limited to a particular aspect of visual language, in addition, the design of letters is a method that is always influenced by the content and thought, it is placed in different cultural and social conditions and reflected in unlimited aesthetic forms. Situation that occurs with Iranian literature that owes its value to the writings and the words. On the other hand, in the field of art, especially the art of letter design, it is this writing that plays the central role. Almost more than a century ago, new and modern phenomena slowly came to Iran, and Iranian artists began to use modern art.

What is gleaned from the research is the introduction of typography as a powerful and usable tool not only in the international community but also as an art of communication on the Iranian border and examining its most important function; visual communication and the transfer of information and content. It is also discovered how the forms of typography evolve and its impact on contemporary Iranian art. The descriptive research work was carried out through the process of reviewing and collecting information from the library documents.

Keywords: Modern; Modern Art; Form; Typography

\section{RESUMEN}

Hoy en día, el diseño de letras ya no es solo una forma de transmitir información, sus características visuales y estructurales no se limitan a un aspecto particular del lenguaje visual, además, el diseño de las letras es un método que siempre está influenciado por el contenido y el pensamiento, se coloca en diferentes condiciones culturales y sociales y se refleja en formas estéticas ilimitadas. Situación que ocurre con la literatura iraní que debe su valor a los escritos y las palabras. Por otro lado, en el campo del arte, especialmente el arte del diseño de letras, es esta escritura la que juega el papel central. Hace casi más de un siglo, los nuevos y modernos fenómenos llegaron lentamente a Irán, y los artistas iraníes comenzaron a utilizar el arte moderno.

Lo que se extrae de la investigación es la introducción de la tipografía como una herramienta poderosa y utilizable no solo en la comunidad internacional sino también como un arte de comunicación en la frontera de Irán y examinando su función más importante; la comunicación visual y la transferencia de información y contenido. También se descubre cómo evolucionan las formas de la tipografía y su impacto en el arte iraní contemporáneo. El un trabajo de investigación descriptivo y se llevó a cabo mediante el proceso de revisión y recopilación de información de los documentos de la biblioteca.
\end{abstract}

Palabras clave: moderno; arte moderno; forma; tipografía 


\section{Introduction}

As we know today, typography has become a very important and widely used art of communication in the international community. Talking and thinking about it nowadays seems more necessary than ever before because it is a cultural issue and therefore needs to be addressed. The emphasis and thinking on it, especially in the graphic design culture, is extremely tangible. Reading is accepted as the main function of typography, and typography is the most common and unmatched element of graphic communication. The graphic designer must know typography very well. That's because the most accurate, clear and rational way of providing any kind of information is good typography. Of course, beauty and aesthetics are undeniable facts, but the most important thing is to have a meaningful conversation.

The penetration and expansion of graphics in different areas of social and individual life of the public brings with it an understanding of the image and the practical uses of form and color for the general public, which can be seen even in today's Iranian thinking and worldviews.

It can be said that all countries in their communication with other countries in the field of art, especially graphics have a great impact, but still use their past and artistic background. Likewise, modern art is the product of modern thought and an aesthetic response to its demands. This art is the product of the intellectual, social and historical developments of the modern age and the result of its scientific and theoretical achievements. The emergence of modernism in the field of art has always been associated with a pragmatic character, and so all artistic theories and modernist stylistic approaches have been automatically spun into a scientific campaign.

Throughout its many millennia of history, Iran has been constantly exposed to cultural transformations .Iranian culture has become accustomed to the flexibility of the plant to preserve its essence and dynamism. A culture that has long been rooted in history and exposed its branches not only to the breeze, not to the storm, not to the storm and to the broken, but to the joy of every storm, an unmistakable dance, sitting on the floor of every earth so full of stillness Let's taste the sweetness of its fruits. Therefore, in the present study, we have tried to study the art of typography and the forms created and the impact it has received from modern times and modern art, and finally to analyze examples of contemporary Iranian typography influenced by art. Moderns have evolved in form and we have presented contemporary and unmatched art in the form of typography in contemporary times. In fact, the main question of this study is how do modern technology and the tools of modern life play a role in the balanced development of the structure of Persian writing in contemporary Iran?

\section{Theoretical Foundations}

\section{Typography}

Typography is taken from two words (type) and (graphy) that translate (letter design), but the definition is provided (graphic alignment of letters and typewritten words). Typography of alphabets, alphabet design and modification of letters, location and size of letters on the page and ratio of all letters to the appropriate paper level with golden fit; The spacing between words and rows is to observe the intensity of the letters in color alongside the other colors and to combine them with all the visual components of a page. It is arguable that any typographic layout forms a (even abstract) picture of a text. Initially, the art of graphics was one of the technical activities such as industrial skills. Later, the need to coordinate activities and inform customers of the best choice led to the separation of the designer and executor. The graphic designer received instructions from the custome, prepared the plan and then guided the technical expert, the typewriter and the printer to realize the plan (Einsley,2010, 3).

\section{Modern}

The modern word, derived from the Latin root of modo or mo, means today or what is common today. Modern in different eras and places, it is used to distinguish contemporary styles from traditional, and can be applied to virtually any area of life. (Lawrence, 2002, 11).

The word abstraction is equivalent to the word modernity, which is used to describe human beings or societies and civilizations and historical periods. This concept is to move in the direction of transforming thought, art, way of life, and in short, everything related to life, and it has a fundamentally Western meaning (Jahanbeglou, 2013, 239).

\section{Modern art}

Modern art is the product of modern thinking and an aesthetic response to its demands. This art is the product of the intellectual, social and historical developments of the modern age and the result of its scientific and theoretical achievements. The emergence of modernism in the field of art has always been associated with a pragmatic character, and so all artistic theories and modernist stylistic approaches have spontaneously led to a scientific campaign. 
There is a disagreement between historians and art scholars about exactly when modern art begins and what artwork, art style, art movement, or even art discourse we can call the starting point of modern art. Some consider modern art to be the art of the twentieth century. Others, including American researcher Christopher Whitcomb, believe that modern art began in the 1980s with the display of a luncheon on Edward Manet's lawn in the Paris Mard and lasted until the mid-1980s.

Art for Art is a completely modernist discourse that, rather than the artist's attention to you, allows you to appear as a complete representation of the visual, personal and color assemblies. An artist who has come to terms with your point of view, you can present yourself as another photo and suggest ideas, using the limitations of modernity and romantic expression in recent years(Sami Azar, 2013, 10-11)

\section{Modern Art Indicators}

Some art critics in the twentieth century believe that some of the features of modern art can be considered more prominent than others

First, the visual artist of the twentieth century does not merely confine himself to stylistic changes and employs new materials in his field while using traditional tools, materials and materials. The result is not only stylistic changes, but also the transformation of the concept of painting and sculpture and their standard definition. The next characteristic is the emphasis on the autonomy of art and the pursuit of the ideal of art for art

The expansion of formalist tendencies and theories of philosophers such as Clive Bell and Roger Fry are to reinforce formalism in visual art. However, in the early decades of the twentieth century, more and more visual artists are turning from figuration or abstraction to abstraction or abstraction. But this process is not a lasting process, and abstract art cannot be considered the top genre of modern art.

The next feature is the challenging nature, the outburst, the aggression, and (at its most mildly) criticism of modern art. Another feature is the experience of philosophical elements and the use of abstract elements in the construction of new forms whether spatial, temporal, in plays or in color, form, perspective, volume, surface and other basic principles of visual arts. Attention to the general audience and the creation of comprehensible forms for the general audience and attention to the dynamics and critique of art, and to some extent the rationality of art by manipulating the basic elements of art, are other features of modern art. (Linton, 2009, 4)

Among all the various forms of modern art that have been crystallized in its various styles and styles. A relatively general feature distinguishes modernism from pre-modern artistic views, and is nothing but an internal and structural look at art itself.

\section{Concept of form in art}

The combination of elements that make up a single set, the manner and style that coordinate these elements, and in short, form the factor that bestows a unique personality on the set (Bahrami, 2013, 138). Each part of each letter has its name, which refers to the negative form or space inside or around the so-called counter form. The form is a positive space. Form counter refers to the negative space that is enclosed within or around a form.

In contemporary Iranian typographic art, artists have been able to create unique typographic forms in various ways. They have greatly influenced the evolution of forms by applying various techniques such as change, composition, substitution, visualization, and so on.

\section{Form changes}

In this cover design, (Figure 1) the black forearm adds a visual layer to the text layer of the word disaster by adding a few explosive spots. The semantic burden of the word disaster adds more depth to the audience with the addition of blots. 


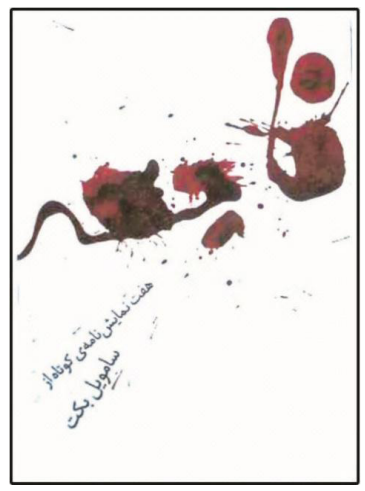

Figure 1. Form changes

\section{Form composition}

Form composition one form of transformation is the combination of several strategies together called form combinations. When a letter is combined with another form, (in the form of symbols or abstracts), the form is called the combination of two images

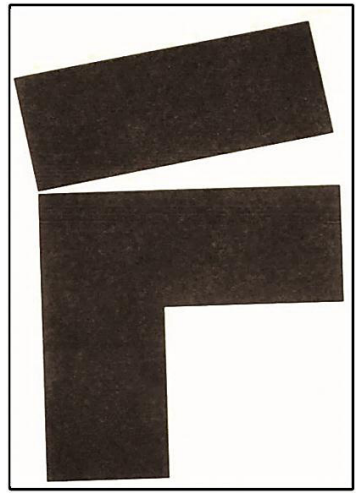

Figure 2. Form changes

\section{Form replacement}

Replacing a known letter or object form or other symbol is called substitution. Substituting one form for another is a form of visual inclusion, but because the image is a successor to the talk, a very different visual connection is obtained.

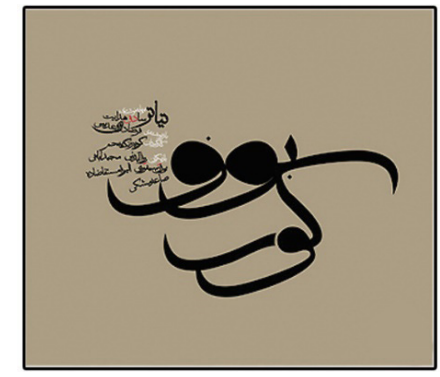

Figure 3. Blind Owl (Poster Designer, Farzad Adibi)

\section{Illustration}

When letters become a representation of a real object, it is visualized. They may interact with other real elements such as figures or environments. (Figure 4). For example, figurines interact with the lettering element, as if it is what it represents. Alternatively, the letters can be independent of other images but begin to resemble a real object 
(Meskali, 2011, 126-112).

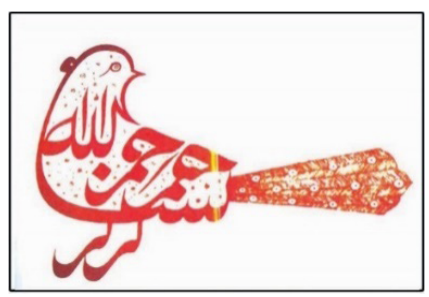

Figure 4. Illustration

Sometimes designers and artists who design innovation and beauty for the sole purpose of visual aesthetics have used techniques such as overlapping letters, adapting or overlapping letters, picking up letters, and shuffling letters. The group has gone so far as to incorporate letters such as painting, pure form, and to create a stream of formalism in today's graphic art (Figure 5). (Khazaei, 2006: 11).

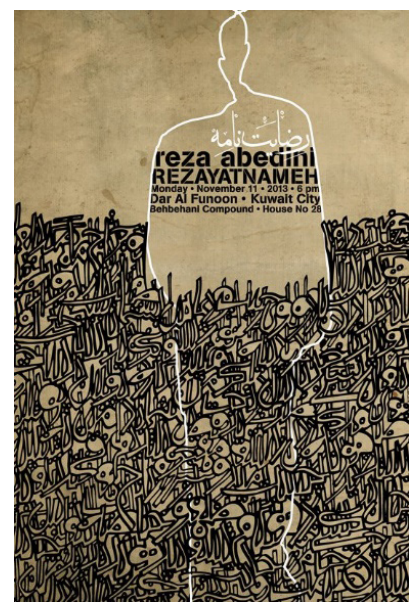

Figure 5. Formalist flow letters

Analysis of Contemporary Typographical Types of Iran Morteza Momiz, who is called the graphic father of Iran. If we do not count the number of works that are designed and executed in each discipline and only consider some of them, the thoughtful and creative designs in each of these excerpts are few and even sufficient to reveal the modern mind. This transparency is the character of the river

The Deer Movie Poster (Figure 6) is one of the most popular posters designed for Iranian cinema. The design of this poster is superb and modern in its timing. The arrangement the artist made to design this work contains the content of the film. This effect, while simple, has a profound effect on the audience. At the time, he designed the movie poster's black and white using the film's face image and stereotyped instrumentation and the use of three reds. (Figure 3-43) Examples of Morteza posters are prohibited.

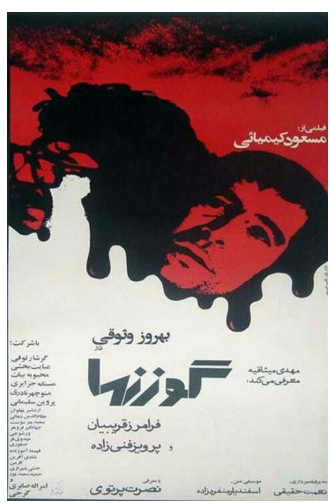

Figure 6. Deer Poster, Designer: Morteza Momiz 
Another contemporary Iranian graphic artist, Ghobad Shiva, a great Iranian designer and painter, was born in the city of Hamedan in the year 6, and has been able to transform contemporary typography through his unique artworks. The artist's posters are designed and decorated with handwritten or handwritten texts. Many of his works have a painterly style, and often handwritten writings, the titles of the work as a whole being handwritten, often covering much of the volume.

The poster for the first Textile Design Exhibition (Figure 7) shows text that covers the entire volume of the poster and forms the title of the work. As the title suggests, the work uses a variety of colors to represent fabrics with different textures and backgrounds. Also the people around this article are seen in different colors (different ethnicities). Latin and vertical text on the right side and Persian text on the bottom right represent poster information. (Figure 4-6) are examples of Shiva Qobad posters

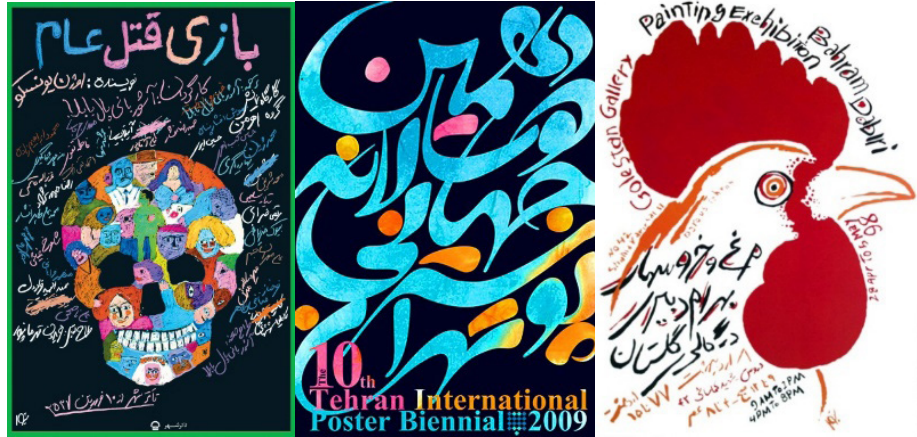

Figure 7. Sample posters of Qobad Shiva

Another artist who was able to make a mark in typography and create new and unmatched forms in contemporary Iran is Mohammad Esaie. The statue is considered by the founder of line painting in Iran, because he was the first to use letters as a means of expression. He used visual and conceptual design elements and arrays in his calligraphy. One of his works, "What is Truth," is a graphic combination of words and letters that are beautifully intertwined and intertwined.

This work is different in design and composition from the artist's earlier works. According to the poster, which is a conceptual phrase that has a semantic metaphor that engages the audience and makes them think what the truth is. In this work, the artist depicts combinations of his cheekbones with white and black outlines on a blue background and yellow dots. The text, which is the main element in this work, is flat and vertical, which is difficult to read for the audience, and corresponds to a conceptual metaphor that comes to mind from the title of the work. (Figure 8) are examples of works by Mohammed Aseaie.

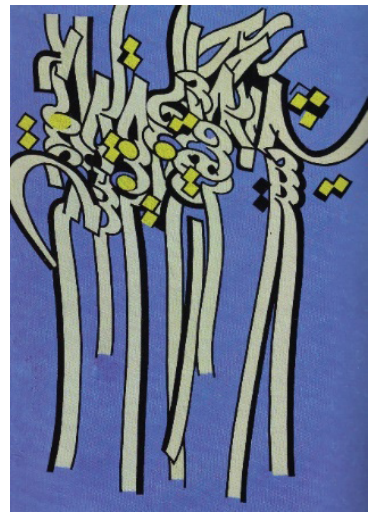

Figure 8. What is the Truth, Designer: Mohammad Esaie

Another major figure in contemporary Iranian graphic design is Ibrahim Haghighi. In the works of the Exhibition of Drawings (Figure 9) it seems that the artist's attempt is to examine the relationship between literature and the visual arts. Ibrahim Haghighi has gone to a poet like Hafiz in the exhibition (Wrong Role).

These paintings were initially separated from the typography, gradually changing from one exhibition to the next. The first designs were written on a flat, monochrome background, and the artist filled the negative space between the lines with complementary colors. For example, orange to represent autumn and blue to represent the night. In addition, the artist still had some indication of the graphic function of the lines in his performance; On the other hand, Ibrahim Haghighi is not a calligrapher, so unlike the calligraphers he avoided the Persian lines and used 
line drawings that are rooted in graphic design. His approach and his paintings are a completely new approach that seeks to depict the intrinsic essence of Persian poetry through the use of non-Iranian imaging tools, which strives to link our literary and cultural essence with modern language.

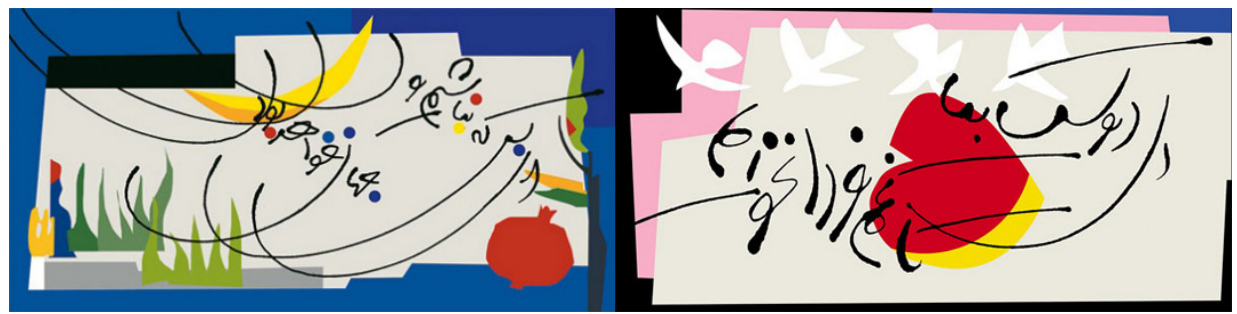

Figure 9. Examples of Drawings Exhibition, Designer: Ebrahim Haghighi

Cyrus the Glass Artist, another artiste who has excelled in the field of graphic and typography in contemporary Iran. It introduces Shah Reza Street(Figure 10) (the current revolution) with all the buildings, cars, shops and pedestrians and everything in it as an artwork. The artist has called his work (art + art)

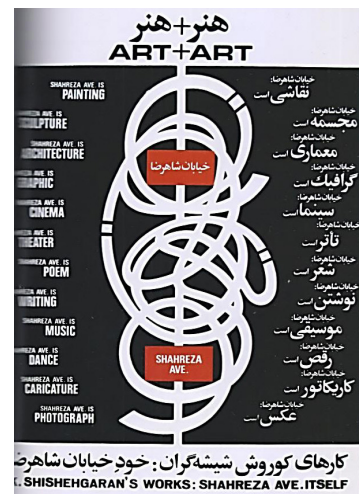

Figure 10. Shahreza Ave. (Male + Art), Designer: Cyrus the Granite Glass

Saad Black is one of the most active graphic artists in contemporary times. What distinguishes him from other designers is the use of different textures, special letters and typefaces and different layout types that make the viewer more familiar with black stylings. He uses limited and specific colors and the techniques are almost identical. Simple works The minimalist tendency is strong in him, both in terms of the number and type of elements used and the number of colors in his works. Even the letters he uses in most of his works are old typewriters that run on paper and evade clarity.

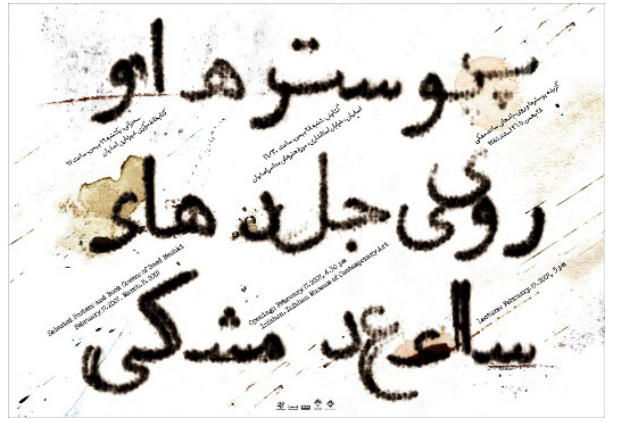

Figure 11. Black forearm poster

\section{Conclusion}

Technology and tools of modern life play an important role in the development of the structure of Persian writing. Digital technologies and modern techniques have greatly influenced the art of graphic design. If in the past, design depended on the artist's skill in using his traditional tools such as brushes, pencils, etc., but today, due to the many advances made by technology, it depends on clicking on the computer mouse or touching the screen of 
devices such as mobile and Etc. Even if they are functionally imitations of traditional tools, they are different in terms of usage and techniques.

Cultural connections between the Iranian art community and modern art have greatly influenced the flourishing of contemporary Persian typography. According to the history of modern art in Iran, the emergence of graphic art today and its main branch, typography, is closely linked to writing. In the history of art, the works created in recent times to the present day, which are the beginnings of periods called modernity, are witnessing a new development in this field.

Socio-economic developments and the introduction of industrialization have made Iranian society more interactive with Western societies, so it has had a profound impact on Western society and their art, resulting in today's form of graphic and typography originating all over. It is from the West and modernity.

\section{REFERENCES}

Bahrami, Mahdi. (2013). The role of form in the payment of Mahdavi content in the visual arts. Mahdavi Scientific Research Quarterly, Second year, No 7, 138-141

Cohen, Lawrence. (2002). Selected texts from modernism to postmodernism. Translated by Abdul Karim Rashidian. Tehran. Ney

Einsley, Jeremy. (2010). A century of graphic design. Translated by Azade Etesam, Mahboubeh Tutunchi. Tehran. Yasavoli Publishing Jahanbeglou, Ramin. (2001). Iran and Modernity. Tehran. Goftar publisher.

Khazaei, Mohammad. (2006). Writing as an image. The first biennial poster typography. Iran. Shahr publishment.

Lenten, Norbert. (2009). Modern Art. Translated by Ali Ramin. Tehran. Ney publisher.

Mesqali, Farshid. (2011). Typography. Tehran. Nazar.

Sami Azar, Alireza. (2013). The birth of Iranian modernism. Tehran. Nazar.

How to cite this article: Rafiei, M., \& Arasteh, J. (2020). An Approach to the Effects of Modern Art on the Evolution of Iranian Contemporary Typography. Religación. Revista de Ciencias Sociales y Humanidades, 5(23), 189-196. Retrieved from http:// revista.religacion.com/index.php/religacion/article/view/617

Submitted: 05 January 2020 Accepted: 19 March 2020 Published: 31 March 2020

Religación. Revista de Ciencias Sociales y Humanidades is a peer-reviewed open access journal published by CICSH-AL Centro de Investigaciones en Ciencias Sociales y Humanidades desde América Latina |Religación| 